\title{
Analysis of aliphatic biopolymers using thermochemolysis with tetramethylammonium hydroxide (TMAH) and gas chromatography- mass spectrometry
}

\author{
JOSE C. DEL RIO'* and PATRICK G. HATCHER ${ }^{1,2}$ \\ 'Department of Geosciences, 209 Academic Projects Building, The Pennsylvania State University. \\ University Park, PA 16802, U.S.A. and "Fuel Science Program, Department of Material Science and \\ Engineering, 209 Academic Projects Building, The Pennsylvania State University, University Park, PA \\ 16802, U.S.A.
}

\begin{abstract}
Selected aliphatic biopolyesters (cutins, cuticles and a suberin) isolated from different plants have been analyzed using thermochemolysis with tetramethylammonium hydroxide (TMAH). This method consists of a high-temperature saponification/transesterification, and yields methyl esters of fatty acids and the methyl ethers of alcohols, which are subsequently analyzed by gas chromatography and gas chromatography-mass spectrometry. The main compounds produced from the analyzed samples correspond to the methyl derivatives of long-chain fatty acids, hydroxy fatty acids and $\alpha, \theta-$ alkanedioic acids. The composition of the released compounds are similar to those reported in the literature using different depolymerization methods. The main advantage of the procedure is that it is easily performed in glass tubes with very low amounts of sample and without additional derivatization steps prior to gas chromatographic analysis because the products are methylated in siru. The method also avoids the laborious and lime consuming sample preparation of extractive methods and the use of large amounts of solvents.
\end{abstract}

Key words-cutin, cuticle, suberin, fatty acids, TMAH/thermochemolysis

\section{INTRODUCTION}

Because cutin and suberin play a key mediating role between higher plants and the environment, their chemical composition and structure have been the subject of numerous investigations (Kolattukudy, 1984; Holloway, 1982; Walton, 1990). Cutin, a biopolyester composed of interesterified hydroxy fatty acids, is found as an external protective barrier on aereal plant surfaces (Kolattukudy, 1980, 1984). Cutin is composed primarily of hydroxylated fatty acids with a high proportion of mid-chain oxygenated acids (Espelié et al, 1979, 1980). The monomer composition of cutin varies among different plant species. In general, angiosperm cutins can be broadly classified into three categories according to the chemical lengths of the predominant fatty acid monomers, that is, a $C_{16}$ type, a $C_{18}$ type and a mixed $C_{16}$ and $C_{18}$ type. The cutins of the gymnosperms and other lower plants generally lack the $C_{18}$ monomer acids (Holloway, 1982). Suberin, a similar biopolymer, serves as a protective barrier for sub- terranean surfaces of plants and its structure is thought to consist of aliphatic polyester domains, composed of aliphatic monomers of long-chain $\left(\mathrm{C}_{16}, \mathrm{C}_{24}\right) \omega$-hydroxy fatty acids and $\alpha, \omega$-dicarboxylic acids, covalently attached to aromatic domains which are in turn attached to the cell wall (Kolattukudy, 1978).

However, despite all the investigations, the intramolecular structure of cutin and suberin is only poorly understood and a detailed characterization of their chemical composition is important for a physiological or chemotaxonomical point of view. Indeed, cutins and suberins are unique to vascular plants and have already been used as a convenient mean for determining the flow of terrestrially derived organic matter in marine environments, and also to discriminate between different vascular plant sources in natural environments (Goni and Hedges, 1990; Opsahl and Benner, 1995).

Partial depolymerization of the aliphatic biopolyesters has been accomplished using various chemical and enzymatic methods, including hydrogenolysis with $\mathrm{LiAlH}_{4}$, hydrolysis with alcoholic $\mathrm{KOH}$ or $\mathrm{HCl}$, and enzymatic degradation with cutinases (Holloway, 1982; Kolattukudy, 1984; Walton, 1990). The identifications of products of the reactions often requires further derivatization to convert the alcohol groups into their trimethylsilyl 
or acetyl derivatives and the carboxyl groups into their respective methyl esters, prior to analysis by capillary gas chromatography.

In a number of papers (Holzer et al., 1988; Dworzanski et al., 1990, 1991; Challinor, 1996) natural esters were converted to their respective methyl esters by tetramethyl- or other tetra-alkylammonium hydroxides under pyrolytic conditions. Dworzanski et al. $(1990,1991)$ used the "pyrolytic methylation" with tetramethylammonium hydroxide (TMAH) for the generation of chemotaxonomically characteristic profiles of fatty acid methyl esters from different bacterial cells. It was demonstrated that the methyl esters were formed by transesterification reactions (via intermediate tetramethylammonium hydroxide salts) and were not formed by methylation of pyrolytically generated fatty acids. Holzer et al. (1989) used a related quaternary amine, trimethylanilinium hydroxide to obtain fatty acid profiles of bacterial cells, while Butte (1983) used trimethylsulphonium hydroxide (TMSH) as a transesterification reagent. Most of the products corresponded to those formed by hydrolysis and quantitative methylation of the fatty acid moieties with partial methylation of the aliphatic hydroxyl groups.

Another technique for analysis of these biopolymers, pyrolysis in the presence of TMAH, has been particularly effective in transforming macromolecular material, composed of esters and phenolic compounds, to monomers by hydrolysis and subsequent alkylation. The volatile monomers are then analyzed quantitatively by gas chromatography/mass spectrometry. Challinor $(1989,1991 \mathrm{a}, \mathrm{b})$ first introduced this technique for the simultaneous pyrolysis and methylation of phenolic polymers. Since then, it has been applied to the structural characterization of bio- and geomacromolecules such as lignins (Martín et al., 1995b; Clifford et al., 1995), humic materials (Saiz-Jiménez et al., 1993, 1994; SaizJiménez, 1994a,b; Hatcher and Clifford, 1994; del Río et al., 1994; Chiavari et al., 1994; Martín et al., 1994, 1995a; Fabbri et al., 1996), whole soils, (Schulten and Sorge, 1995; Schulten et al., 1996), asphaltenes and kerogens (Kralert et al., 1995; del Río et al., 1996b) and natural and fossil resins and resinites (Anderson and Winans, 1991; Clifford and Hatcher, 1995). In particular, several biopolyesters such as the cutin from tomato fruit and the suberin from potato tubers have already been successfully analyzed by pyrolysis/TMAH (de Leeuw and Baas, 1993; González-Vila et al., 1996). The main products formed were the methyl derivatives of fatty acids and hydroxylated fatty acids. Challinor (1996) also used the pyrolysis/TMAH for the rapid profiling of fatty acids in a variety of vegetable oils and animal fats.

Several authors (de Leeuw and Baas, 1993; Hatcher and Clifford, 1994; Martín et al., 1994;
Challinor, 1995; del Río et al., 1996a) have pointed out that the reaction involved in the TMAH/pyrolysis scheme is one of chemolysis rather than pyrolysis. Sub-pyrolysis temperatures have therefore been found to effectively produce a suite of products similar to that observed at higher pyrolysis temperatures (Hatcher and Clifford, 1994; Clifford et al., 1995). In a recent paper (McKinney et al., 1995), a procedure was outlined for the characterization of lignin at subpyrolysis temperatures in the presence of TMAH using sealed glass tubes. Since then, this procedure has been extended to the characterization of lignin in fresh and degraded woods (Hatcher et al., 1995), coalified woods (McKinney and Hatcher, 1996) and the highly aliphatic and resistant biopolymer cutan present in the cuticle of various plants (McKinney et al., 1996).

In this paper, we investigate the use of the sealed tube reaction with TMAH on a set of aliphatic biopolyesters (cuticle, cutin and suberin) isolated from different plants. The main advantage of this procedure is that it is conducted in a glass microreactor, a glass ampoule, as a one-step thermolysis and methylation, with the products being immediately available for analysis by gas chromatography. The procedure avoids the laborious and time-consuming sample preparation of extractive methods and does not require additional derivatization steps.

\section{MATERIALS AND METHODS}

The samples selected for this study were kindly provided by Dr. Karl Espelié and consisted of the cutins isolated from tomato fruit, papaya fruit and lime fruit and the cuticles from Agave Americana and apple fruit. The chalazal region of the inner seed coat of grapefruit (Citrus paradise INSC hilum) was also selected for this study as an example of a suberin polymer. The procedures for the isolation of the different samples have already been reported (Espelié et al., 1980, 1982, 1983).

The samples $(0.5-1.0 \mathrm{mg})$ were weighed precisely and placed in a glass tube with a measured amount $(100 \mathrm{ml})$ of TMAH $(25 \% \mathrm{w} / \mathrm{v}$ in methanol). Triplicate samples of tomato cutin were prepared to verify the reproducibility of the method. The methanol was evaporated under vacuum and the tube sealed under vacuum. The sealed tubes were then placed in an oven at $250^{\circ} \mathrm{C}$ for $30 \mathrm{~min}$. After cooling to room temperature, the tubes were cracked open and all inside surfaces washed out with methylene chloride $(3 \times 1 \mathrm{ml})$. The extracts were combined and reduced to dryness under a stream of nitrogen. The samples were then diluted with a known volume of methylene chloride $(100 \mathrm{ml})$, which contained an internal standard $(28.4 \mathrm{ng} / \mathrm{ml}$ of $n$-eicosane) and subsequently analyzed by capillary gas chromatography (GC) on a Hewlett Packard 5890 Series II gas chromatograph 
and by gas chromatography/mass spectrometry (GC/MS) on a Kratos MS-80 RFA high-resolution gas chromatograph/mass spectrometer system. The columns used for the GC separation were $30 \mathrm{~m} \times 0.25 \mathrm{~mm}$, i.d., fused silica capillary columns (DB-5, J and W). The column was heated at $30^{\circ} \mathrm{C} /$ min from an injection temperature of $60^{\circ} \mathrm{C}$ to a temperature of $100^{\circ} \mathrm{C}$, at which point the rate was slowed to $6^{\circ} \mathrm{C} / \mathrm{min}$ to a final temperature of $300^{\circ} \mathrm{C}$, and held for $10 \mathrm{~min}$. Injector and detector were set at $300^{\circ} \mathrm{C}$.

Mass spectra (electron impact mode) were obtained in the mass range from $m / z 40$ to 600 at a scan rate of $0.6 \mathrm{~s} /$ decade of mass with a $0.2 \mathrm{~s}$ magnet settling time added. Compounds were identified by their mass spectra and relative retention times. Identification of the monomers liberated by TMAH/thermochemolysis has been made through direct comparison of commercially available mass spectral database using computerized library searching and by analysis of mass spectral fragmentation patterns.

\section{RESULTS AND DISCUSSION}

The chromatograms of the products released after TMAH/thermochemolysis of the different aliphatic biopolyesters selected for this study are shown in Fig. 1. The main compounds identified corresponded to the methyl derivatives of longchain fatty acids, hydroxylated fatty acids (the hydroxylated sites being converted by the TMAH to methyl ethers) and dicarboxylic acids. All these products can be rationalized as derived from alkaline hydrolysis of the polyesters into fatty acid monomers, followed by quantitative methylation of the fatty acid monomers. Since hydroxy groups become methylated after TMAH/thermochemolysis, it would not be then possible to distinguish them from naturally occurring methoxy groups; however, this is not the case since methoxy-fatty acids have not been found as forming part of the structure of cutin and suberin.

Tables 1 and 2 show the list of the identified compounds, as well as their relative distribution in the different samples. The distribution of the compounds identified is similar to that previously reported for the monomeric constituents of these samples using different depolymerization methods (Ray et al., 1995; Espelié et al., 1980, 1983; Holloway, 1973, 1982; Baker and Holloway, 1970; Baker et al., 1982). The cutin of tomato fruit was selected to study the reproducibility of the method. Three replicates were performed and the composition determined. Table 2 shows the mean values and the standard deviation of the abundances of the compounds identified in tomato fruit cutin. The average standard deviation is $8 \%$, which indicates that this procedure is very reproducible. In the ensuing discussion, reference is made to hydroxylated fatty acids with the understanding that it is the methylated ester/ethers that are inferred to be the ones detected in our analysis.

As expected, great differences in composition were found between the suberin sample (the chalazal region of the inner seed coat of grapefruit) and the cutins and cuticles. While the suberin sample yielded mainly $\mathrm{C}_{16}, \mathrm{C}_{18}, \mathrm{C}_{22}$ and $\mathrm{C}_{24}$ monomers, the major monomers produced from the cutin and cuticles analyzed in this study have either 16 or 18 carbon atoms or both (Fig. 1), in agreement with literature. The most abundant members of the $\mathrm{C}_{16}$ family identified in these samples were the methyl derivatives of hexadecanoic acid (12), $\omega$-hydroxyhexadecanoic acid (16) and different positional isomers of dihydroxyhexadecanoic acid $(\mathbf{1 9 , 2 0 , 2 1 )}$. Other monomers that can be derived by further oxidation of the common $\mathrm{C}_{16}$ monomers were also detected in some cutins. This is the case of the methyl derivative of the 16-hydroxy-10-oxohexadecanoic acid (17) released from lime cutin. This agrees with prior studies of citrus fruit cutins, in which large proportions of $\omega$-hydroxy-oxo-hexadecanoic acids were found among the hydrogenolysis and alkaline hydrolysis products of grape fruit, lime, lemon, orange, clementine and mandarine (Deas et al., 1974; Espelié et al., 1980, 1983; Baker and Procopiou, 1975). The methyl derivative of the 10-hydroxyhexadecanoic acid (14), also reported in lime cutin and other citrus especies (Ray et al., 1995), was also identified in lime fruit cutin. On the other hand, the major members identified of the $\mathrm{C}_{18}$ family of cutin monomers were the methyl derivatives of octadecanoic acid (15), octadecenoic acid (13), 18-hydroxyoctadec-9-enoic acid (23) and 9,10,18-trihydroxyoctadecanoic acid (30).

The $\mathrm{C}_{16}$ monomers, particularly the methyl derivatives of different positional isomers of dihydroxyhexadecanoic acid, were dominant in the case of tomato fruit, papaya fruit and lime fruit cutins. Tomato fruit cutin also released trace amounts of a $\mathrm{C}_{18}$ monomer, the methyl derivative of the $9,10,18$ trihydroxyoctadecanoic acid (30). Its presence has been shown to be confined to the early stages of fruit development, and is not usually detected in mature tomato fruit cutins (Baker et al., 1982). In the apple fruit and Agave americana cuticles, the $\mathrm{C}_{16}$ and $\mathrm{C}_{18}$ monomers are both dominant, but with a predominance of the $\mathrm{C}_{16}$ monomers in the apple fruit cuticle (mainly the methyl derivatives of the 16-hydroxyhexadecanoic acid, 16 and 10,16dihydroxy-hexadecanoic acid, 21) and a predominance of the $\mathrm{C}_{18}$ monomers in the Agave americana cuticle (mainly the methyl derivative of the $9,10,18$ trihydroxyoctadecanoic acid, 30), in agreement with previously published data (Holloway, 1973; Espelié et al., 1982). 


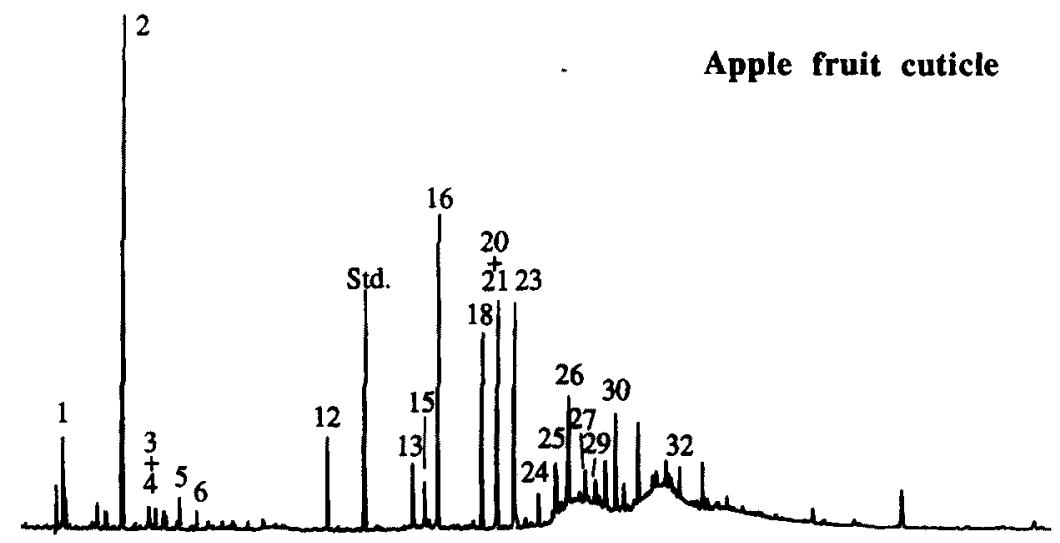

Grapefruit suberin (chalazal region)
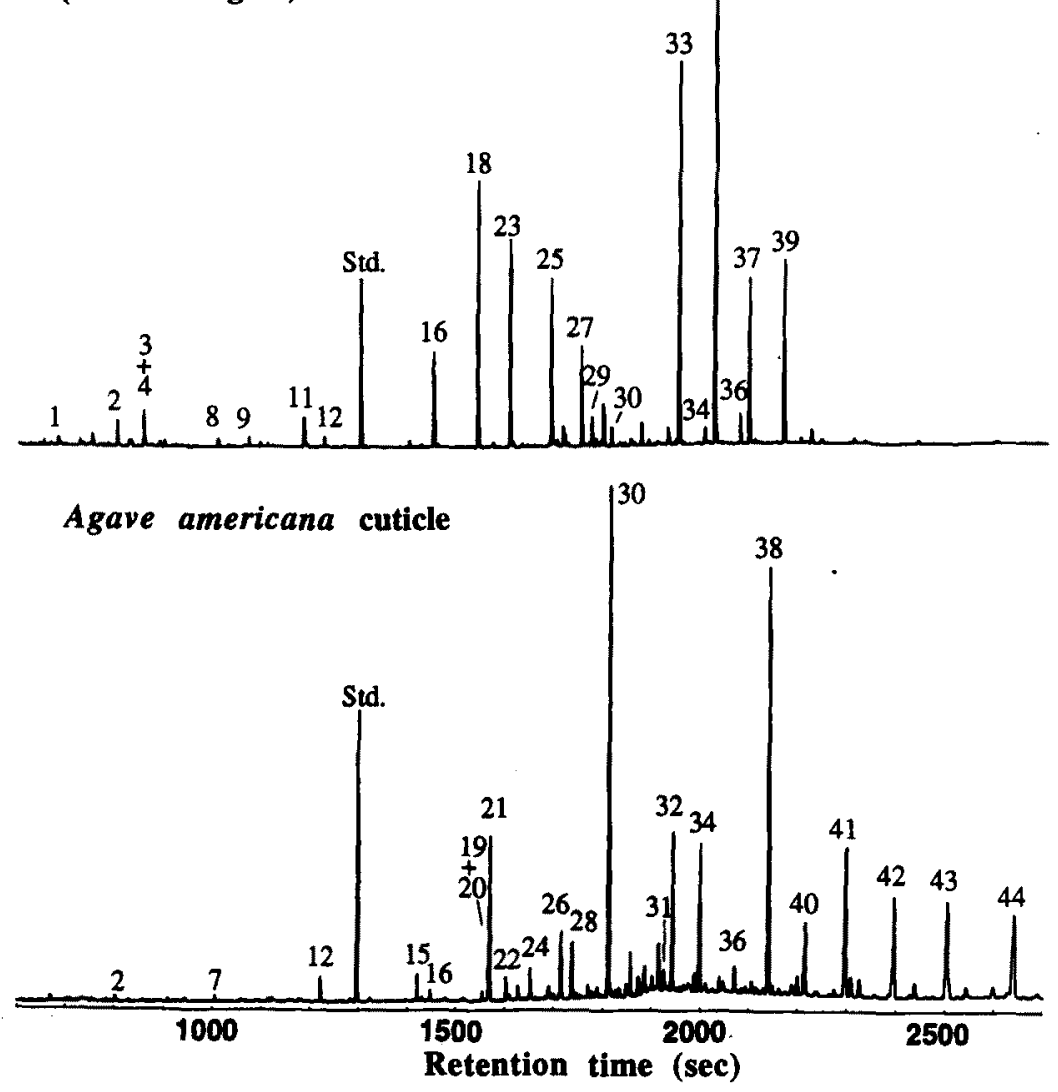

Fig. la.

Dihydroxyhexadecanoic acids are the most characteristic and dominant cutin monomers in plants and are usually found as a mixture of positional isomers, with the mid-chain hydroxyl found at either C-7, C-8, C-9 or C-10, with the latter two isomers being the most prevalent ones (Holloway and Deas, 1971). After TMAH/thermochemolysis, the different positional isomers produce the respective methyl derivatives, which under the chromatographic conditions used, coelute in the same chromatographic peak. However, the mass fragmen- tation pattern of each positional isomer is different and therefore they can be easily detected and quantified by integration of the characteristic fragment ions in the GC-MS. The isomers that were detected in the samples studied were the methyl derivatives of the 8,16-, 9,16- and 10,16-dihydroxy-hexadecanoic acids. Figure 2 shows the structures and mass spectra of the different positional isomers. The characteristic fragment ions in their mass spectra represent cleavage $\alpha$ to the secondary methoxyl group giving a dimethoxy fragment (I) and a meth- 

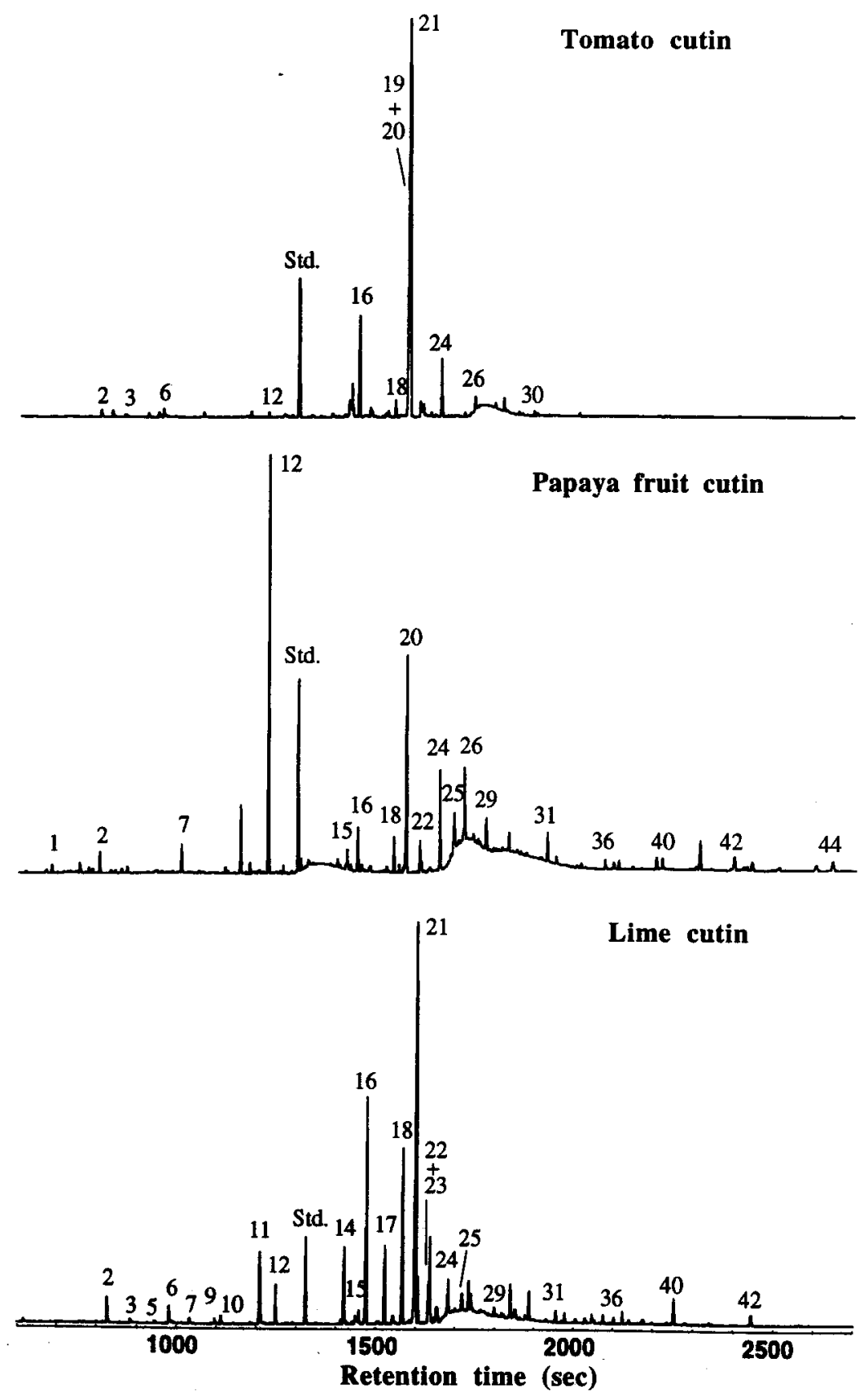

Fig. 1. Gas chromatograms of the TMAH/thermochemolysis products released from the selected samples. The peak numbers correspond to the compounds identified in Tables 1 and 2 . Std: internal standard ( $n$-eicosane).

oxy methyl ester fragment (II). The relative distribution of the different dihydroxyhexadecanoic acid isomers was calculated using the most intense fragment ions of the individual isomers in the GC-MS, assuming that the sensitivity was the same for each isomer. Table 3 shows the composition of the positional isomers of the methyl derivatives of the dihydroxyhexadecanoic acids in the different samples analyzed, which generally agrees with the relative compositional data published in the literature
(Holloway and Deas, 1971; Holloway, 1973; Baker et al., 1982; Espelié et al., 1982; Gérard et al., 1992). Among the different positional isomers of the dihydroxyhexadecanoic acids, the methyl derivative of the 10,16-dihydroxyhexadecanoic acid (21) was the most abundant in all the cutins and cuticles analyzed, except in the papaya fruit cutin, in which the methyl derivative of the 9,16-dihydroxyhexadecanoic acid methyl ester (20) was present almost exclusively. While in the tomato cutin, the methyl 
Table 1. Composition (\%) of the TMAH/thermochemolysis products released from the selected samples

\begin{tabular}{|c|c|c|c|c|c|c|}
\hline Label & Compound & $\begin{array}{l}\text { Papaya fruit } \\
\text { cutin }\end{array}$ & $\begin{array}{l}\text { Lime fruit } \\
\text { cutin }\end{array}$ & $\begin{array}{l}\text { Apple fruit } \\
\text { cuticle }\end{array}$ & $\begin{array}{c}\text { Paradise INSC } \\
\text { hilum }\end{array}$ & $\begin{array}{l}\text { Agave americana } \\
\text { cuticle }\end{array}$ \\
\hline 1 & octane-1,8-dioic acid dimethyl ester & 0.7 & 0 & 3.0 & 0.6 & 0 \\
\hline 2 & nonane-1,9-dioic acid dimethyl ester & 1.4 & 1.3 & 22.4 & 1.0 & 0 \\
\hline 3 & cis 3-(4-methoxyphenyl)-3-propenoic acid methyl ester & 0 & 0.3 & 0.9 & 1.4 & 0 \\
\hline 4 & 3,4-dimethoxybenzenecarboxylic acid methyl ester & 0 & 0 & 0 & 0 & 0 \\
\hline 5 & decane-1,10-dioic acid dimethyl ester & 0 & 0.3 & 1.3 & 0 & 0 \\
\hline 6 & trans 3-(4-methoxyphenyl)-3-propenoic acid methyl ester & 0 & 1.2 & 0.8 & 0 & 0 \\
\hline 7 & tetradecanoic acid methyl ester & 2.0 & 0.3 & 0 & 0 & 0.3 \\
\hline 8 & 3,4,5-trimethoxybenzenecarboxylic acid methyl ester & 0 & 0 & 0 & 0 & 0 \\
\hline 9 & cis 3-(3,4-dimethoxyphenyl)-3-propenoic acid methyl ester & 0 & 0.2 & 0 & 0 & 0 \\
\hline 10 & pentadecanoic acid methyl ester & 0 & 0.4 & 0 & 0 & 0 \\
\hline 11 & trans 3-(3,4-dimethoxyphenyl)-3-propenoic acid methyl ester & 0 & 4.1 & 0 & 1.4 & 0 \\
\hline 12 & hexadecanoic acid methyl ester & 32.6 & 1.8 & 3.2 & 0.4 & 0.7 \\
\hline 13 & octadec-9-enoic acid methyl ester & 0 & 0 & 2.4 & 0 & 0 \\
\hline 14 & 10-methoxy-hexadecanoic acid methyl ester & 0 & 3.8 & 0 & 0 & 0 \\
\hline 15 & octadecanoic acid methyl ester & 1.8 & 0.6 & 1.6 & 0 & 0.8 \\
\hline 16 & 16-methoxy-hexadecanoic acid methyl ester & 3.2 & 12.8 & 12.1 & 3.6 & 0.4 \\
\hline 17 & 16-methoxy-10-oxo-hexadecanoic acid methyl ester & $\mathbf{0}$ & 3.9 & 0 & 0 & 0 \\
\hline 18 & hexadecane-1,16-dioic acid dimethyl ester & 2.6 & 9.5 & 7.3 & 10.4 & 0 \\
\hline $19 / 20 / 21$ & 8,16-, 9,16- and 10,16-dimethoxy-hexadecanoic acid methyl esters & 18.6 & 33.3 & 9.5 & 0 & 6.0 \\
\hline 22 & eicosanoic acid methyl ester & 3.1 & 2.1 & 0 & 0 & 0.7 \\
\hline 23 & 18-methoxy-octadec-9-enoic acid methyl ester & 0 & 0 & 9.7 & 8.5 & 0 \\
\hline 24 & mixt. of hydroxy-methoxy hexadecanoic acid methyl ester & 7.3 & 3.7 & 1.3 & $\mathbf{0}$ & 1.1 \\
\hline 25 & octadec-9-ene-1,18-dioic acid dimethyl ester & 4.0 & 1.0 & 3.7 & 6.9 & 0 \\
\hline 26 & 9,10,16-trimethoxyhexadecanoic acid methyl ester & 5.8 & 0 & 4.4 & 0 & 2.6 \\
\hline 27 & dimethoxyoctadecenoic acid methyl ester (tentatively) & 0 & 0 & 1.5 & 3.8 & 0 \\
\hline 28 & 10,18-dimethoxyoctadecanoic acid methyl ester & $\mathbf{0}$ & 0 & 0 & 0 & 2.1 \\
\hline 29 & docosanoic acid methyl ester & 2.7 & 0.5 & 1.3 & 1.4 & 0 \\
\hline 30 & 9,10,18-trimethoxy-octadecanoic acid methyl ester & 0 & 0 & 3.7 & 0.8 & 18.8 \\
\hline 31 & tetracosanoic acid methyl ester & 2.2 & 0.5 & 0 & 0 & 0.9 \\
\hline 32 & 9,10,12,18-tetramethoxyoctadecanoic acid methyl ester & 0 & 0 & 1.1 & 0 & 5.0 \\
\hline 33 & 22-methoxy-docosanoic acid methyl ester & 0 & 0 & 0 & 15.7 & 0 \\
\hline 34 & hexacosanol methyl ether & 0 & 0 & 0 & 0.8 & 4.6 \\
\hline 35 & docosane-1,22-dioic acid dimethyl ester & 0 & 0 & 0 & 22.2 & 0 \\
\hline 36 & hexacosanoic acid methyl ester & 0.8 & 0.5 & 0 & 1.2 & 1.2 \\
\hline 37 & 24-methoxy-tetracosanoic acid methyl ester & 0 & 0 & 0 & 6.8 & 0 \\
\hline 38 & octacosanol methyl ether & 0 & 0 & 0 & 0 & 15.2 \\
\hline 39 & tetracosane-1,24-dioic acid dimethyl ester & 0 & 0 & 0 & 7.8 & 0 \\
\hline 40 & octacosanoic acid methyl ester & 1.1 & 1.6 & 0 & 0 & 3.4 \\
\hline 41 & triacontanol methyl ether & 0 & 0 & 0 & 0 & 7.1 \\
\hline 42 & triacontanoic acid methyl ester & 2.0 & 0 & 0 & 0 & 5.9 \\
\hline 43 & dotriacontanol methyl ether & 0 & 0 & 0 & 0 & 6.6 \\
\hline \multirow[t]{2}{*}{44} & dotriacontanoic acid methyl ester & 1.4 & 0.8 & 0 & 0 & 6.2 \\
\hline & unknowns & 6.7 & 15.5 & 8.8 & 5.3 & 10.4 \\
\hline
\end{tabular}




\begin{tabular}{llr}
\hline Label & Compound & \multicolumn{1}{c}{$\begin{array}{c}\text { Abundance } \\
(\%)\end{array}$} \\
\hline 2 & nonane-1,9-dioic acid dimethyl ester & $0.4 \pm 0.07$ \\
3 & cis 3-(4-methoxyphenyl)-3-propenoic acid methyl ester & $0.8 \pm 0.06$ \\
6 & trans 3-(4-methoxyphenyl)-3-propenoic acid methyl ester & $2.8 \pm 0.10$ \\
12 & hexadecanoic acid methyl ester & $0.5 \pm 0.06$ \\
16 & 16-methoxy-hexadecanoic acid methyl ester & $9.3 \pm 1.40$ \\
18 & hexadecane-1,16-dioic acid dimethyl ester & $2.1 \pm 0.05$ \\
$19 / 20 / 21$ & 8,16-, 9,16-, 10,16-dimethoxy-hexadecanoic acid methyl ester & $72.5 \pm 2.45$ \\
24 & mixture of hydroxy-methoxy hexadecanoic acid methyl ester & $5.7 \pm 0.30$ \\
26 & $9,10,16-$ trimethoxyhexadecanoic acid methyl ester & $1.0 \pm 0.12$ \\
30 & $9,10,18$-trimethoxy-octadecanoic acid methyl ester & $0.4 \pm 0.02$ \\
& unknowns & $4.5 \pm 0.05$ \\
\hline
\end{tabular}

derivatives of the dihydroxyhexadecanoic acids account for nearby $70 \%$ of the total monomers, in lime cutin they comprise around $33 \%$ and papaya fruit cutin around $18 \%$. Minor amounts were found in the cuticles of apple fruit and Agave americana $(10 \%$ and $6 \%$ respectively). Some relatively low amounts of hydroxymethoxyhexadecanoic acid methyl ester, corresponding to partially methylated hydroxyl groups, were also identified as products, although in far lower amounts than in pyrolysis/ TMAH experiments (de Leeuw and Baas, 1993).

In contrast to dihydroxyhexadecanoic acids, dihydroxyoctadecanoic acids are not common components of cutins. However, the methyl derivative of the 10,18-dihydroxyoctadecanoic acid (28) could be identified after TMAH/thermochemolysis of the Agave americana cuticle, as also reported by other authors (Matic, 1956). A wide range of positional isomers $(9,18-, 11,18-$ and 12,18-) were found to coelute in the same chromatographic peak, although in minor amounts, as demonstrated by their fragmentation pattern in the mass spectrometer. The main characteristic fragments are $\mathrm{m} / \mathrm{z}$ 187 and $215(10,18-), m / z 201(9,18-), m / z 173$ and 229 (11,18-) and $m / z 159$ and 243 (12,18-dimethoxyoctadecanoic acid methyl ester).

Among the trihydroxy fatty acids, the most common are the trihydroxyoctadecanoic acids, in particular the 9,10,18-trihydroxyoctadecanoic acid. Its methyl derivative, the $9,10,18$-trimethoxyoctadecanoic acid methyl ester (30) was found as an important component of the TMAH/thermochemolysis products of apple fruit and Agave americana cuticles. Trihydroxyhexadecanoic acids, in particular the methyl derivative of the 9,10,16-trihydroxyhexadecanoic acid (26) was also present in minor amounts in the cutins of tomato fruit and in higher amounts in papaya fruit cutin, apple fruit cuticle and Agave americana cuticle. The methyl derivatives of more hydroxylated fatty acids, such as 9,10,12,18-tetramethoxyoctadecanoic acid methyl ester (32), were also detected in the cuticles of apple fruit and Agave americana.

A series of fatty alcohol methyl ethers and fatty acid methyl esters up to $C_{32}$, with strong even car- bon number predominances and maxima at $\mathrm{C}_{28}$, were also produced from TMAH thermochemolysis of the cuticle of Agave americana. These compounds arise from the transesterification of the cuticular waxes.

The suberin sample selected for this study corresponds to the chalazal region of the inner seed coat of grapefruit. This sample yielded primarily the methyl derivatives of the $\omega$-hydroxy fatty acids $\mathrm{C}_{16}$, $\mathrm{C}_{18: 1}, \mathrm{C}_{22}$ and $\mathrm{C}_{24}$, and their corresponding dicarboxylic acids. Minor amounts of the methyl derivatives of phenolic compounds ( $p$-coumaric acid, 3 and ferulic acid, 9, 10) were also detected, as well as minor amounts of 9,10,18-trimethoxyoctadecanoic acid methyl ester (30). The distribution of the monomeric constituents is in agreement with previously published work using depolymerization with LiAlH $_{4}$ and LiAlD $_{4}$ (Espelié et al., 1980).

It is known that epoxy fatty acids usually occur as major monomers in some cutins (Holloway and Deas, 1973). The use of $\mathrm{LiAlH}_{4}$ reduction or methanolysis shows that large amounts of 9,10-epoxy-18hydroxy octadecanoic acid occurs among the products of depolymerization of apple fruit and Agave americana cuticles (Kolattukudy et al., 1971; Walton and Kolattukudy, 1972; Holloway and Deas, 1973; Espelié et al., 1982). However, no epoxy fatty acids could be identified after TMAH/ thermochemolysis. While the method does not affect most monomeric units, the epoxy fatty acids seem to be converted to other compounds. To confirm whether the epoxy group is destroyed during the procedure, an epoxy fatty acid standard, the 9,10epoxyhexadecanoic acid methyl ester, was subjected to the TMAH/thermochemolysis procedure. It was found that the 9,10-epoxy group is mainly converted to a 9,10-dimethoxy group, with minor amounts of partially methylated hydroxy-fatty acids. Therefore, we would expect a compound such as 18-hydroxy-9,10-epoxyoctadecanoic acid to be mainly converted to the $9,10,18$-trimethoxyoctadecanoic acid methyl ester upon treatment with TMAH, and so, the concentration of this compound is likely to reflect the contents of both epoxides and ether-linked components in the aliphatic 

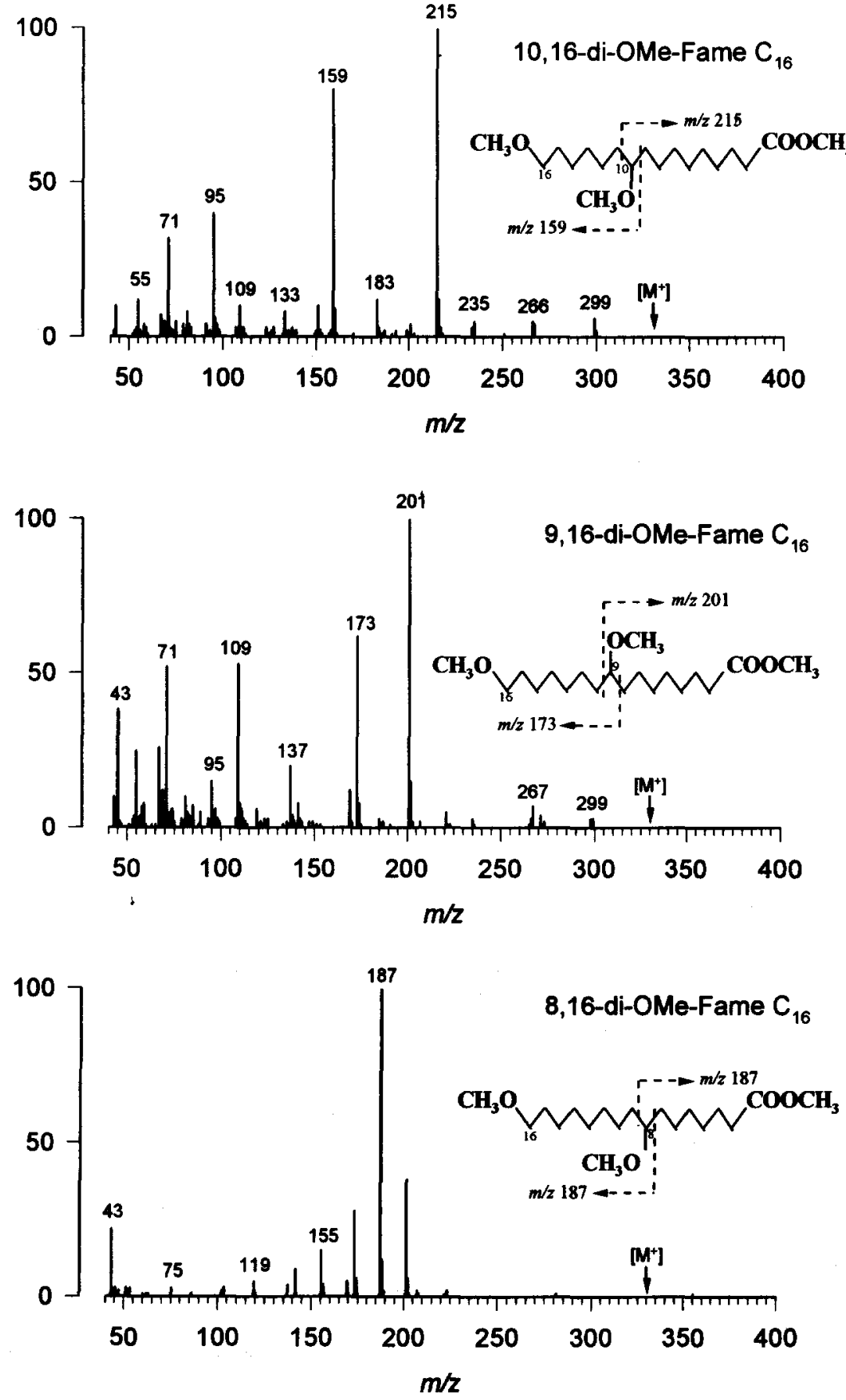

Fig. 2. Structures and mass spectra of the different dimethoxyhexadecanoic acid methyl ester isomers.

Table 3. Composition (\%) of the different positional isomers of dimethoxyhexadecanoic acid methyl ester occurring in the different samples

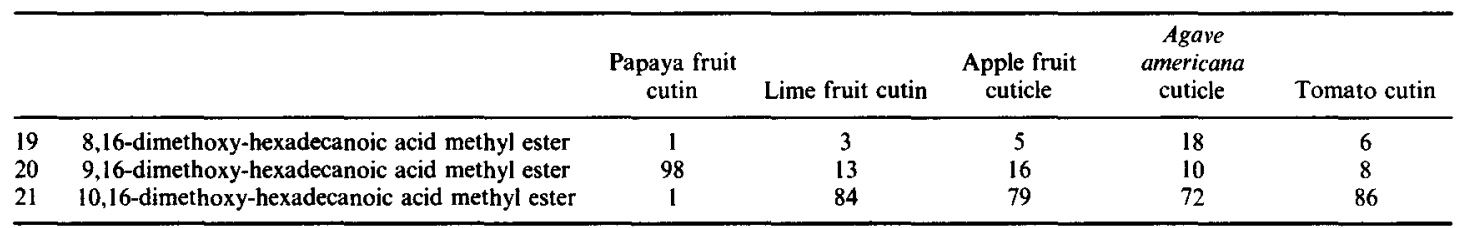


Gérard, H. C., Moreau, R. A., Fett, W. F. and Osman, S. F. (1992) Separation and quantification of hydroxy and epoxy fatty acids by high performance liquid chromatography with an evaporite light-scattering detector. Journal of the American Oil Chemists' Sociey 69, 301 304.

González-Vila, F. J., del Río, J. C., Martín, F. and Verdejo, T. (1996) Pyrolytic alkylation-gas chromatography-mass spectrometry of model polymers: further insights into the mechanism and scope of the technique. Journal of Chromatography 750, 155-160.

Goñi, M. A. and Hedges, J. I. (1990) Potential applications of cutin-derived $\mathrm{CuO}$ reaction products for discriminating vascular plant sources in natural environments. Geochimica et Cosmochimica Acta 54, 3073-3083.

Hatcher, P. G. and Clifford, D. J. (1994) Flash pyrolysis and in situ methylation of humic acids from soil. Organic Geochemistry 21, 1081-1092.

Hatcher, P. G., Nanny, M. A., Minard, R. D., Dible, S. C. and Carson, D. M. (1995) Comparison of two thermochemolytic methods for the analysis of lignin in decomposing gymnosperm wood: the $\mathrm{CuO}$ oxidation method and the method of thermochemolysis with tetramethylammonium hydroxide (TMAH). Organic Geochemistry 23, 881-888.

Holloway, P. J. (1982) The chemical constitution of plant cutins. In The Plant Cuticle, eds. D. F. Cutler, K. L. Alvin and C. E. Price, pp. 45-85. Academic Press, New York.

Holloway, P. J. (1973) Cutins of Malus pumila fruits and leaves. Phytochemistry 12, 2913-2920.

Holloway, P. J. and Deas, A. H. B. (1971) Occurrence of positional isomers of dihydroxyhexadecanoic acid in plant cutins and suberins. Phytochemistry 10, 27812785.

Holloway, P. J. and Deas, A. H. B. (1973) Epoxyoctadecanoic acids in plant cutins and suberins. Phytochemistry 12, 1721-1735.

Holzer, G., Bourne, T. F. and Bertsch, W. (1989) Analysis of in situ methylated microbial fatty acid constituents by Curie-point pyrolysis-gas chromatography-mass spectrometry. Journal of Chromatography 468, 181-190.

Kolattukudy, P. E. (1978) Chemistry and biochemistry of the aliphatic components of suberin. In Biochemistry of Wounded Plant Tissues, ed. G. de Kahl, pp. 43-84. De Gruyter, Berlin.

Kolattukudy, P. E. (1980) Biopolyester membranes of plants: cutin and suberin. Science 208, 990-1000.

Kolattukudy, P. E. (1984) Biochemistry and function of cutin and suberin. Canadian Journal of Botany 62, 2918-2933.

Kolattukudy, P. E., Walton, T. J. and Kushwaha, R. P. S. (1971) Epoxy acids in the lipid polymer cutin and their role in the biosynthesis of cutin. Biochemical and Biophysical Research Communications 42, 739-744.

Kralert, P. G., Alexander, R. and Kagi, R. I. (1995) An investigation of polar constituents in kerogen and coal using pyrolysis-gas chromatography-mass spectrometry with in situ methylation. Organic Geochemistry 23, 627639.

de Leeuw, J. W. and Baas, W. (1993) The behaviour of esters in the presence of tetramethylammonium salts at elevated temperatures: flash pyrolysis or flash chemolysis? Journal of Analytical and Applied Pyrolysis 26, 175184.

Martín, F., González-Vila, F. J., del Río, J. C. and Verdejo, T. (1994) Pyrolysis derivatization of humic substances, 1. Pyrolysis of fulvic acids in the presence of tetramethylammonium hydroxide. Journal of Analytical and Applied Pyrodysis 28, 71-80.
Martín, F., del Río, J. C., González-Vila, F. J. and Verdejo, T. (1995a) Pyrolysis derivatization of humic substances, 2. Pyrolysis of soil humic acids in the presence of tetramethylammonium hydroxide. Journal of Analytical and Applied Pyrolysis 31, 75-83.

Martín, F., del Río, J. C., González-Vila, F. J. and Verdejo, T. (1995b) Thermally assisted hydrolysis and alkylation of lignins in the presence of tetra-alkylammonium hydroxides. Journal of Analytical and Applied Pyrolysis 35, 1-13.

Matic, M. (1956) The chemistry of plant cuticles: a study of cutin from Agave americana $\mathrm{L}$. The Biochemical Journal 63, 168-176.

McKinney, D. E. and Hatcher, P. G. (1996) Characterization of peatified and coalified wood by tetramethylammonium hydroxide (TMAH) thermochemolysis. International Journal of Coal Geology 32, 217 228.

McKinney, D. E., Carson, D. M., Clifford, D. J., Minard, R. D. and Hatcher, P. G. (1995) Off-line thermochemolysis vs flash pyrolysis for the in situ methylation of lignins: is pyrolysis necessary? Journal of Analytical and Applied Pyrolysis 34, 41-56.

McKinney, D. E., Bortiatynsky, J. M., Carson, D. M., Clifford, D. J., de Leeuw, J. W. and Hatcher, P. G. (1996) Tetramethylammonium hydroxide (TMAH) thermochemolysis of the aliphatic biopolymer cutan: insights to its chemical structure. Organic Geochemistry 24, 641-650.

Opsahl, S. and Benner, R. (1995) Early diagenesis of vascular plant tissues: lignin and cutin decomposition and biogeochemical implications. Geochimica et Cosmochimica Acta 59, 4889-4904.

Ray, A. K., Lin, Y. Y., Gérard, H. C., Chen, Z.-J., Osman, S. F., Fett, W. F., Moreau, R. A. and Stark, R. E. (1995) Separation and identification of lime cutin monomers by high performance liquid chromatography and mass spectrometry. Phytochemistry 38, 1361-1369.

del Río, J. C., González-Vila, F. J., Martín, F. and Verdejo, T. (1994) Characterization of humic acids from low rank coals by ${ }^{13} \mathrm{C}-\mathrm{NMR}$ and pyrolysis/methylationz: formation of benzenecarboxylic acid moieties during coalification process. Organic Geochemistry 22, $885-891$.

del Rio, J. C., Martín, F. and González-Vila, F. J. (1996a) Thermally assisted hydrolysis and alkylation as a novel pyrolytic approach for the structural characterization of natural biopolymers and geomacromolecules. Trends in Analytical Chemistry 15, 70-79.

del Río, J. C., González-Vila, F. J., Martín, F. and Verdejo, T. (1996b) Chemical structural investigation of asphaltenes and kerogens by pyrolysis/methylation. Organic Geochemistry 23, 1009-1022.

Saiz-Jiménez, C. (1994a) Analytical pyrolysis of humic substances: pitfalls, limitations and possible solutions. Environmental Science and Technology 28, 1773-1780.

Saiz-Jiménez, C. (1994b) Pyrolysis/methylation of soil fulvic acids: benzenecarboxylic acids revisited. Environmental Science and Technology 28, 197-200.

Saiz-Jiménez, C., Hermosín, B. and Ortega-Calvo, J. J. (1993) Pyrolysis/methylation: a method for structural elucidation of the chemical nature of aquatic humic substances. Water Research 27, 1693-1696.

Saiz-Jiménez, C., Ortega-Calvo, J. J. and Hermosín, B. (1994) Conventional pyrolysis: a biased technique for providing structural information on humic substances? Naturwissenschaften 81, 28-29.

Schulten, H.-R. and Sorge, C. (1995) Pyrolysis/methylation-mass spectrometry of whole soils. European Journal of Soil Science 46, 567-579.

Schulten, H.-R., Leinweber, P. and Theg, B. K. G. (1996) Characterization of organic matter in an 
Gérard, H. C., Moreau, R. A., Fett, W. F. and Osman, S. F. (1992) Separation and quantification of hydroxy and epoxy fatty acids by high performance liquid chromatography with an evaporite light-scattering detector. Journal of the American Oil Chemists' Sociey 69, 301304.

González-Vila, F. J., del Río, J. C., Martín, F. and Verdejo, T. (1996) Pyrolytic alkylation-gas chromatography-mass spectrometry of model polymers: further insights into the mechanism and scope of the technique. Journal of Chromatography 750, 155-160.

Goñi, M. A. and Hedges, J. I. (1990) Potential applications of cutin-derived $\mathrm{CuO}$ reaction products for discriminating vascular plant sources in natural environments. Geochimica et Cosmochimica Acta 54, 3073-3083.

Hatcher, P. G. and Clifford, D. J. (1994) Flash pyrolysis and in situ methylation of humic acids from soil. Organic Geochemistry 21, 1081-1092.

Hatcher, P. G., Nanny, M. A., Minard, R. D., Dible, S. C. and Carson, D. M. (1995) Comparison of two thermochemolytic methods for the analysis of lignin in decomposing gymnosperm wood: the $\mathrm{CuO}$ oxidation method and the method of thermochemolysis with tetramethylammonium hydroxide (TMAH). Organic Geochemistry 23, 881-888.

Holloway, P. J. (1982) The chemical constitution of plant cutins. In The Plant Cuticle, eds. D. F. Cutler, K. L. Alvin and C. E. Price, pp. 45-85. Academic Press, New York.

Holloway, P. J. (1973) Cutins of Malus pumila fruits and leaves. Phytochemistry 12, 2913--2920.

Holloway, P. J. and Deas, A. H. B. (1971) Occurrence of positional isomers of dihydroxyhexadecanoic acid in plant cutins and suberins. Phytochemistry 10, 27812785.

Holloway, P. J. and Deas, A. H. B. (1973) Epoxyoctadecanoic acids in plant cutins and suberins. Phytochemistry 12, 1721-1735.

Holzer, G., Bourne, T. F. and Bertsch, W. (1989) Analysis of in situ methylated microbial fatty acid constituents by Curie-point pyrolysis-gas chromatography-mass spectrometry. Journal of Chromatography 468, 181-190.

Kolattukudy, P. E. (1978) Chemistry and biochemistry of the aliphatic components of suberin. In Biochemistry of Wounded Plant Tissues, ed. G. de Kahl, pp. 43-84. De Gruyter, Berlin.

Kolattukudy, P. E. (1980) Biopolyester membranes of plants: cutin and suberin. Science 208, 990-1000.

Kolattukudy, P. E. (1984) Biochemistry and function of cutin and suberin. Canadian Journal of Botany 62, 2918-2933.

Kolattukudy, P. E., Walton, T. J. and Kushwaha, R. P. S. (1971) Epoxy acids in the lipid polymer cutin and their role in the biosynthesis of cutin. Biochemical and Biophysical Research Communications 42, 739-744.

Kralert, P. G., Alexander, R. and Kagi, R. I. (1995) An investigation of polar constituents in kerogen and coal using pyrolysis-gas chromatography-mass spectrometry with in situ methylation. Organic Geochemistry 23, 627639.

de Leeuw, J. W. and Baas, W. (1993) The behaviour of esters in the presence of tetramethylammonium salts at elevated temperatures: flash pyrolysis or flash chemolysis? Journal of Analytical and Applied Pyrolysis 26, 175184.

Martín, F., González-Vila, F. J., del Río, J. C. and Verdejo, T. (1994) Pyrolysis derivatization of humic substances, 1. Pyrolysis of fulvic acids in the presence of tetramethylammonium hydroxide. Journal of Analytical and Applied Pyrotysis 28, 71-80.
Martín, F., del Río, J. C., González-Vila, F. J. and Verdejo, T. (1995a) Pyrolysis derivatization of humic substances, 2. Pyrolysis of soil humic acids in the presence of tetramethylammonium hydroxide. Journal of Analytical and Applied Pyrolysis 31, 75-83.

Martín, F., del Río, J. C., González-Vila, F. J. and Verdejo, T. (1995b) Thermally assisted hydrolysis and alkylation of lignins in the presence of tetra-alkylammonium hydroxides. Journal of Analytical and Applied Pyrolysis 35, 1-13.

Matic, M. (1956) The chemistry of plant cuticles: a study of cutin from Agave americana L. The Biochemical Journal 63, 168-176.

McKinney, D. E. and Hatcher, P. G. (1996) Characterization of peatified and coalified wood by tetramethylammonium hydroxide (TMAH) thermochemolysis. International Journal of Coal Geology 32, 217228.

McKinney, D. E., Carson, D. M., Clifford, D. J., Minard, R. D. and Hatcher, P. G. (1995) Off-line thermochemolysis vs flash pyrolysis for the in situ methylation of lignins: is pyrolysis necessary? Journal of Analytical and Applied Pyrolysis 34, 41-56.

McKinney, D. E., Bortiatynsky, J. M., Carson, D. M., Clifford, D. J., de Leeuw, J. W. and Hatcher, P. G. (1996) Tetramethylammonium hydroxide (TMAH) thermochemolysis of the aliphatic biopolymer cutan: insights to its chemical structure. Organic Geochemistry 24, 641-650.

Opsahl, S. and Benner, R. (1995) Early diagenesis of vascular plant tissues: lignin and cutin decomposition and biogeochemical implications. Geochimica et Cosmochimica Acta 59, 4889-4904.

Ray, A. K., Lin, Y. Y., Gérard, H. C., Chen, Z.-J., Osman, S. F., Fett, W. F., Moreau, R. A. and Stark, R. E. (1995) Separation and identification of lime cutin monomers by high performance liquid chromatography and mass spectrometry. Phytochemistry 38, 1361-1369.

del Río, J. C., González-Vila, F. J., Martín, F. and Verdejo, T. (1994) Characterization of humic acids from low rank coals by ${ }^{13} \mathrm{C}-\mathrm{NMR}$ and pyrolysis/methylationz: formation of benzenecarboxylic acid moieties during coalification process. Organic Geochemistry 22, $885-891$.

del Rio, J. C., Martín, F. and González-Vila, F. J. (1996a) Thermally assisted hydrolysis and alkylation as a novel pyrolytic approach for the structural characterization of natural biopolymers and geomacromolecules. Trends in Analytical Chemistry 15, 70-79.

del Río, J. C., González-Vila, F. J., Martín, F. and Verdejo, T. (1996b) Chemical structural investigation of asphaltenes and kerogens by pyrolysis/methylation. Organic Geochemistry 23, 1009-1022.

Saiz-Jiménez, C. (1994a) Analytical pyrolysis of humic substances: pitfalls, limitations and possible solutions. Environmental Science and Technology 28, 1773-1780.

Saiz-Jiménez, C. (1994b) Pyrolysis/methylation of soil fulvic acids: benzenecarboxylic acids revisited. Environmental Science and Technology 28, 197-200.

Saiz-Jiménez, C., Hermosín, B. and Ortega-Calvo, J. J. (1993) Pyrolysis/methylation: a method for structural elucidation of the chemical nature of aquatic humic substances. Water Research 27, 1693-1696.

Saiz-Jiménez, C., Ortega-Calvo, J. J. and Hermosín, B. (1994) Conventional pyrolysis: a biased technique for providing structural information on humic substances? Naturwissenschaften 81, 28-29.

Schulten, H.-R. and Sorge, C. (1995) Pyrolysis/methylation-mass spectrometry of whole soils. European Journal of Soil Science 46, 567-579.

Schulten, H.-R., Leinweber, P. and Theg, B. K. G. (1996) Characterization of organic matter in an 
interlayer claymorganic complex from soil by
pyrolysis/methylation mass spectromeiry. Gothermo 69 $105-118$.

Walton, T. J. (1990) Waxes, cutin and suberin: Methods in Plom Biochentistry 4, 105-158.
Walton. T. J, and Kolallukudy, P. E. (1972) Determination of the siructure of cutin monomers by a novel depolymerization procedure and combined gas chromatography and mass spectrometry. Biothemistry, 11, 1885-1897. 